\section{ON THE CO-EFFICIENT OF EXPANSION OF GAS SOLUTIONS.}

F. L. Nichols ANd A. W. Wheeler.

The dilatometers used in this research differ essentially from those generally employed in the measurement of the expansion of liquids. Their form is shown in the accompanying figure. The bulb (B) contained about $286 \mathrm{grms}$. of the liquid-[ at $15^{\circ} \mathrm{C}=286.3425 \mathrm{grms}$.]

The dilatometer having been filled was placed in the bath in the position denoted in the figure. The lower end $(l)$ of the vertical part of the neck was then immersed in mercury by slldina up the adjustable mercurv tube $(m)$ to the proper point. Upon cooling the liquid, the mercury rose in the neck of the dilatometer and from its height at various temperatures the volume of the solution was calculated.

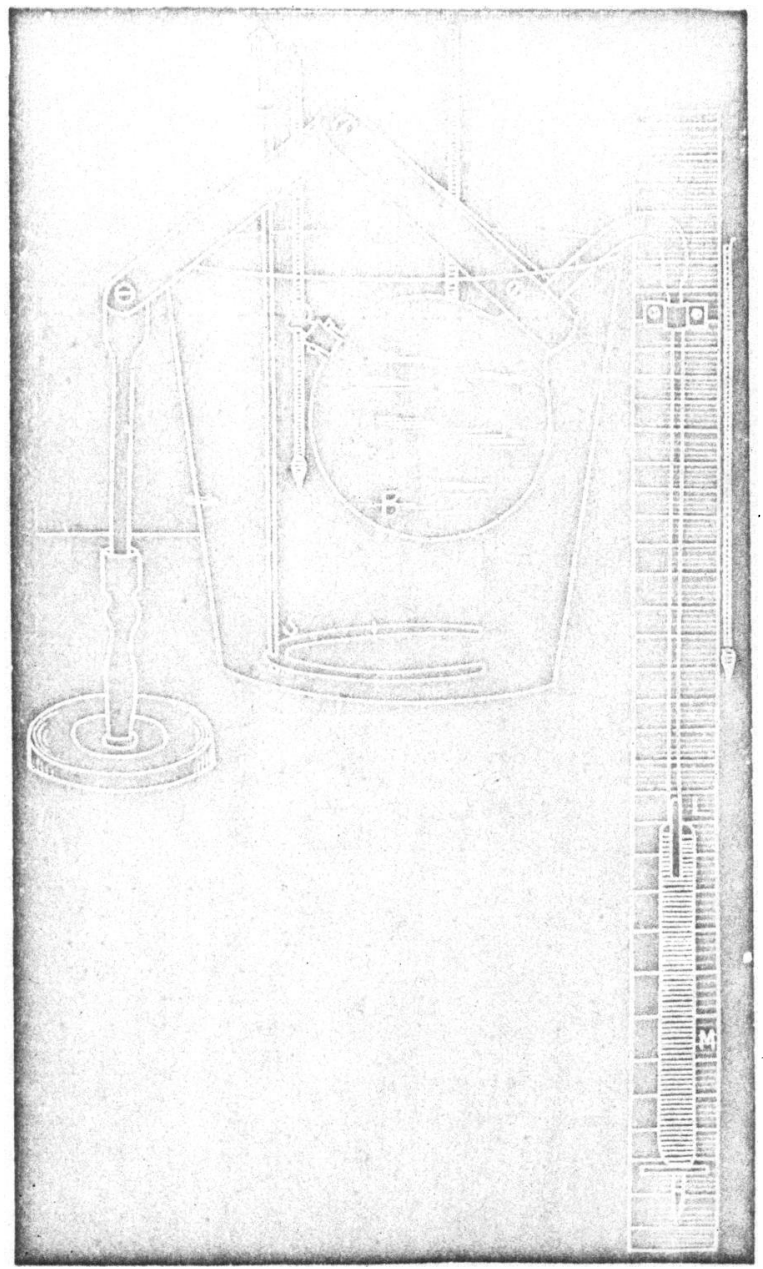

This method was found to be of very great sensitiveness but its accuracy depends upon the careful observance of the following precautions. The neck must be accurately calibrated, the pressure must be kept nearly constant by readjusting, from time to time, the mercury-tube $(m)$. Especial study must be made of the time which will elapse after each change of temperature; before the contents of the dilatometer will have assumed the same temperature as the bath. The authors found this interval of time to be 30 minutes for $1^{\circ}$ and $2^{\circ}$ intervals of temperature and $35 \mathrm{~min}$ utes for a $5^{\circ}$ change. The bath itself must be constantly stirred. Finally the thermometers studied and not only their freezing points and boiling points ascertained, but a careful comparison must be made with some standard thermometer which in turn has been properly calibrated and compared directly with the air thermometer.

The following solutions of ammonia gas were used :

\begin{tabular}{|c|c|c|}
\hline Number. & $\begin{array}{l}\text { Percentage } \\
\text { of } \mathrm{NH}_{3} \text {. }\end{array}$ & $\begin{array}{l}\text { Specific } \\
\text { Gravity. } \\
\text { at } 14^{\circ} \mathrm{C} \text {. }\end{array}$ \\
\hline 5 & $\begin{array}{r}29.00 \\
16.29 \\
7.96 \\
5.68 \\
2.12\end{array}$ & $\begin{array}{l}.9009 \\
.9373 \\
.0673 \\
.9766 \\
.9913\end{array}$ \\
\hline
\end{tabular}

Of these the volumes at various temperatures from +20 ${ }^{\circ} \mathrm{C}$ to the freezing points of the solutions or in the case of the stronger solutions to $-20^{\circ} \mathrm{C}$ were determined and the point of maximum density and freezing points noted. In the following table the volumes of each solution are com. pared with a unit volume of the same solution at $+4^{\circ} \mathrm{C}$.

TABLE. Gas.

Volumes (observed values) of Aqueous Solution of $\mathbf{N H}_{\mathbf{s}}$

\begin{tabular}{|c|c|c|c|c|c|}
\hline \multicolumn{2}{|c|}{$\begin{array}{c}\text { (Water)* Per Cent. } \\
\text { NH, }_{2}=0 . \infty\end{array}$} & \multicolumn{2}{|c|}{ PER CENT. $\mathrm{NH}_{3}=2.12$} & \multicolumn{2}{|c|}{ Per Cent. $\mathrm{NH}_{2}=5.62$. } \\
\hline Temps. & Volumes. & Temps. & Volumes. & Temps. & Volumes. \\
\hline 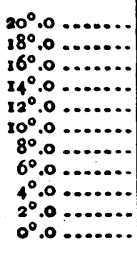 & $\begin{array}{l}1.001744 \\
1.001148 \\
1.000949 \\
1.000701 \\
1.000451 \\
1.000345 \\
1.000114 \\
1.000030 \\
1.000000 \\
1.000073 \\
1.000092\end{array}$ & 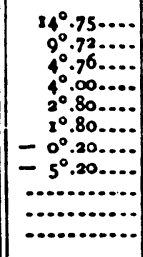 & 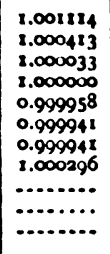 & 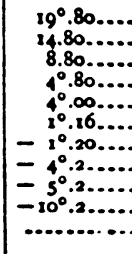 & $\begin{array}{l}1.003180 \\
. .001953 \\
1.000726 \\
1.000106 \\
1.000000 \\
0.099594 \\
0.999398 \\
0.994298 \\
0.999272 \\
0.999289 \\
\ldots \ldots \ldots . .\end{array}$ \\
\hline
\end{tabular}

* The water volumes are taken from Rosetti's table. - Wulluer Phyrik Bd. III.

\begin{tabular}{|c|c|c|c|c|c|}
\hline \multicolumn{2}{|c|}{ PER CRNt. NH -7.96} & \multicolumn{2}{|c|}{$\begin{array}{l}\text { PER CENT. } \\
\mathrm{NH}_{3}=16.19 .\end{array}$} & \multicolumn{2}{|c|}{$\begin{array}{l}\text { Per Cent. } \\
\mathrm{NH}_{3}=29.00 .\end{array}$} \\
\hline Tem & Volu & $\mathbf{T}$ & Volu & Temps. & Volumes. \\
\hline 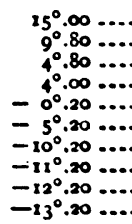 & $\begin{array}{l}1.002662 \\
1.001191 \\
1.000141 \\
1.000000 \\
0.949417 \\
0.998432 \\
0.498740 \\
0.998733 \\
0.995760 \\
0.998794\end{array}$ & 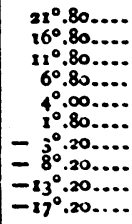 & $\begin{array}{l}1.007129 \\
1.004930 \\
1.002874 \\
1.001013 \\
1.000000 \\
0.999110 \\
0.997514 \\
0.990095 \\
0.49+890 \\
0.994139\end{array}$ & $\begin{array}{r}5 \\
4 \\
3 \\
- \\
-\end{array}$ & 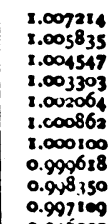 \\
\hline & & & & $=6^{\circ}$ & $\begin{array}{l}0.946020 \\
0.994838 \\
0.993585\end{array}$ \\
\hline
\end{tabular}

From these observed volumes the co-efficients of expan. sion were calculated and curves showing the volumes and co-efficients were plotted. The co-efficient curves are valuable in the determination of the points of maximum den. sity, since they cut the base line at that point at a con. siderable angle, and serve to fix the temperature within $0.1^{\circ} \mathrm{C}$.

The solutions of $2.12,5.61$, and 7.96 per cent. strength froze within the temperature interval reached by the common salt and ice freezing mixture used: the stronger solutions however remained in the liquid state. The following table gives the points of maximum density and the freezing points of the solutions :

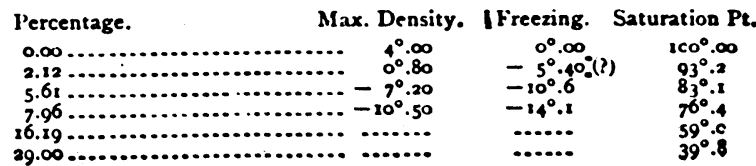


It will be seen from these tables that the effect of ammo. nla gas In solution upon tho wnter absorbing it is to in. crease greatly the co-ceficient of expansion and to lower very rapidly both the points of maximum density and of freezing.

In these respects the gas acts just as a salt in solution would do. Gas solution and salt solution would scem to be closely related phenomena, each resulting in the formation of a mixed liquid, viz: of a liquid composed of two sets of independently moving molecules.

The effect of ammonia gas upon the volume of the water absorbing it is expressed by the following law :

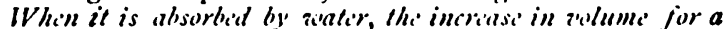
constant temperaturie is divectly froportional in the amount of gas absorbid.

This may be shown to be for $\mathrm{N}$ ll, gas in water by plotting a set of curves with the volumes given in the above tables as oxdinates and percentages of gas as abcissae. These curves, whatever temperatures be chosen, resolve themselves into straight lines. Since for the casc of $\mathrm{CO}_{2}$ gas in water the same law had been already lound true by direct measurement of the change of volume due to the absorption of the gas at cunstant temperitures, we are warranted in suspecting the law to be a gencral one.

\section{THE ENDUCRANIU.I AND MAXILLARY SUS- PENSIRIUM OF THE BEE.}

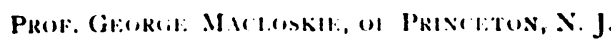

The endocranium of insects is produced by infoldings of the cranial wall, and although several groups (as Diptera, Ilemiptera, Coleoptera, Lepidoptera,) have been represented as devoid of such structures, Prof. Macloskic finds an endocranium present in all these orders. The posterior or epicranial part of the skull has no internal processes. The clypeus, or "tace," has a thick posterior ridge (just in advance of the antenna). From this ridge descend, in bees and allied insects, two meso-cephalic pillars, reaching to the floor of the cranium, in front of the great foramen. These two pillars support the roof of the skull. Ther orcur, with variations, in squashbug, gadfly, mosquito, butterfly, and dragontly. In the cockroach they take the form of a perforated plate, being united anteriorly by a cross-bar (which binds the mandibles together), and being webbed excepting at the centre. (Iluxlev's description of this in his Anatomy of the Invertebrates is inaccurate.)

The maxill:e and labium of the bee are supported by a long framework with elbows and hinges. This suspen. sorium is incorrectly represented in published figures. It is, in part correctly figured by Wolff, who misinterprets it (as if it were on the type of the mammalian skull). Its basal or posterior rods are attached close to the great foramen and to the base of the meso-cephalic pillars, and they are united by a thick web to the base of the skull. The mid-segment, consisting of a pair of bars, supports the maxilla and upon it is an anterior pair of bars supporting the latium. In its working, this frame-work embodies the principle of a recent patent for pruducing steady moticn.

The methods by which the maxilla and labium are protruded and withdrawn were described, al so the relations and mode of working of the pharynx-parts in the mouth. The discovery of a double set of salivary glands was reported: a cephalic set supplying the inner tongue on the floor of the mouth, and the thoracic glands, sending their long duct forward to the labium. The inner structure of the bee's head was shown to be of the same pattern as in other insects, though varied in details. The paper was illustrated by diagrams and microscopic preparations.

\section{NEW PLANETARY NEBULA.}

BY PROFESTOR PICKERING

He described the observations of the planetary nebula, are now in progress at the Harvard College Obser. vatory. Besides measuring the light of these bodies, the opectrum of each has been oxamined by inserting a prism betweon the objective and eyeplece of the larro relescope. A stai is converted into a colored line of light, but the nebulac, being nearly monochromatic, appears as a bright point. The difference is so marked thit the idea suggested itself that by this means planetary nebulie might be discovered, whose disks are so small that they can not otherwise be distinguished from stars. A search was accordingly undertaken on the evening of July 13 th, by sweeping or moving the telescope so that a great number of stars could be examined in a short time. In a few minutes such a nebula was found, which with an ordinary eye-piece might readily be mistaken for a twelfth magnitude star. A similar object was also detected on the next evering. After this, sweeps on several evenings failed to reveal any new nebulae, although it is estimated that the spectlat of oier a hundred thousand stars were examined.

On night before last, while continuing this work, an object with a remarkable spectrum enterid the ticld. The light appeared to consist mainly of a band in the green, a line in the red and probably a fainter band in the yellow, the whole being superposed on a faint continuous spectrum. The new stars which blazed out in Corona in 1563 and in Cyg. nus in 1876 , presented for a short time a similar spectrum, but with this exception the star noted above appears to be unigue. It is too soon to form a theory regarding the nature of this bods, as clouds interrupted the olservations and barely allowed time for its identification. It proved to be the star known as Oeltzen $176 j t$, and must therefore have had nearly its present brightuess forty vears ago.

The field for discovery by the method here given is far from being exhausted since, less than one hundreth part of the heavens has as yet been examined.

\section{ON LAND SNAILS OF THE PALEOZOIC PERIOD.} By DR. D.lwsox, F. R. S... Princip.l of McGill Universı!y.

The land snails occurring in the carboniferous and Devonian systems, of which six species are known, were no. ticed in detail. Two of these, Pupa Bissliii from the coal formation of Nova Scotia. and Strophitis srandicza from the Erian (Devonian) of St. Johns, New Brunstvick, were described for the first time. Four of the known species belong to the different subdivisions of the old genus Pupa, and two are helicord or snail. like in form. They constitute a very isolated group of tossils, as none are known in older formations, and there are none newer till we reach the early Tertiary. Though all of somewhat distinct types, they all belong to one great family or sub-order of the Pulmonifira. and are all closely allied to types still living. All the species hitherto found are American, four being found in Nova Scotia and New Brunswick, and two in Illinois. The latter were discovered and described by the late $\mathbf{M r}$. Bradley. Pufa vitusta, the ear!iest known, was found in the material filling a hcllow Sirillaria, by Sir Charles Lyell and Dr. Dawson in 1851 . In ine paper, which will probably appear in full in the Amrkicax Jouksile of Scitscr. figures and descriptions of all the species are given, and their atfinities and mode of occurrence are discussed.

\section{FURTHER NOTES ON THE POLLINATION OF YUCCA AND ON PRONUBA AND PRODOXUS. BY C. Y. RILEY.}

The author refers t. the origrinal paper on the Fructitication of Vilcea read alt the Dubufue (1s-2) meeting of the Association and notice's virtous criticisms sinte mite upon its conclusions. The paper shows that none of the'se eriticisms were warranted, and verities the orminal observattions and conclusions by stabsequent experience. Itpoints out the causes of error in that other writers have confounded related moths having similar seneral appearance but great structural differences and different habits. The characters of the Bogus Yucca Moth (Prodoxus dicipiens), are given, and five new 